
GOVERNMENT OF LIBERIA and the AGENCY FOR INTERNATIONAL DEVELOPMENT U.S. DEPARTMENT OF STATE

\title{
AEROMAGNETIC MAP \\ OF THE GBANKA QUADRANGLE, LIBERIA \\ By
}

John C. Behrendt and Cletus S. Wotorson

FOLIO OF THE GBANKA QUADRANGLE, LIBERIA

MAP I-776 B

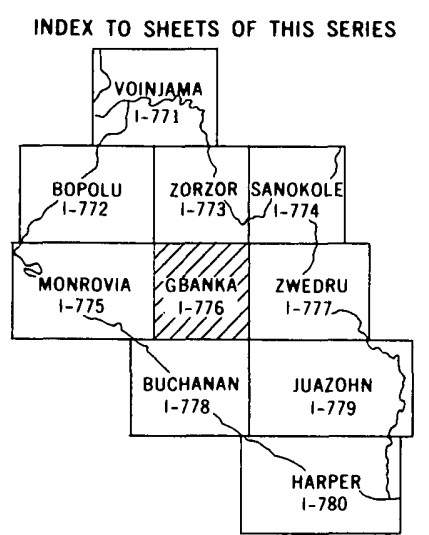

PUBLISHED BY THE U. S. GEOLOGICAL SURVEY RESTON, VA. 22092 